\title{
Human hepatocyte carcinogenesis (Review)
}

\author{
HIDENORI SHIRAHA $^{1}$, KAZUHIDE YAMAMOTO $^{1}$ and MASAYOSHI NAMBA ${ }^{2}$ \\ ${ }^{1}$ Department of Gastroenterology and Hepatology, Okayama University Faculty of Medicine, \\ Okayama 700-8558; ${ }^{2}$ Niimi College, Nishikata 1263-2, Niimi 718-8585, Japan
}

Received September 10, 2012; Accepted October 22, 2012

DOI: 10.3892/ijo.2013.1829

\begin{abstract}
Hepatocellular carcinoma is the third most frequent cause of cancer-related death worldwide; and its incidence rate is increasing. Clinical and molecular medical analyses have revealed substantial information on hepatocarcinogenesis. Hepatocarcinogenesis is a stepwise process during which multiple genes are altered. Genetic changes and their biological consequences in human HCC can be divided into at least 4 groups: i) tumor suppressor genes (p53, retinoblastoma, phosphatase tensin homolog and runt-related transcription factor 3), ii) oncogenes (myc, K-ras, BRAF), iii) reactivation of developmental pathways (Wnt, hedgehog), and iv) growth factors and their receptors (transforming growth factor- $\alpha$, insulin-like growth factor-2 receptor). An experimental model of human hepatocarcinogenesis such as in vitro neoplastic transformation of human hepatocytes has not been successfully achieved yet, but several immortalized human hepatocyte cell lines have been established. These immortalized human hepatocytes will become useful tools for the elucidation of hepatocarcinogenesis, especially for the initial step of multistep hepatocarcinogenesis.
\end{abstract}

\section{Contents}

1. General aspects of hepatocellular carcinoma

2. Molecular alterations in human HCC

3. Experimental hepatocarcinogenesis in vitro

Correspondence to: Dr Hidenori Shiraha, Department of Gastroenterology and Hepatology, 2-5-1 Shikata-cho, Okayama 700-8558, Japan

E-mail: hshiraha@md.okayama-u.ac.jp

Abbreviations: HCC, hepatocellular carcinoma; HBV, hepatitis B virus; $\mathrm{HCV}$, hepatitis $\mathrm{C}$ virus; $\mathrm{Rb}$, retinoblastoma; $\mathrm{LOH}$, loss of heterozygoty; PTEN, phosphatase and tensin homolog; RUNX3, runt-related transcription factor 3; APC, adenomatous polyposis coli; $\mathrm{PTCH}$, patched; SMO, smoothened; TGF- $\alpha$, transforming growth factor- $\alpha$; IGF-2, insulin-like growth factor-2; TGF- $\beta$, transforming growth factor- $\beta$; TERT, telomerase reverse transcriptase; SV40, simian virus 40

Key words: hepatocarcinogenesis, tumor suppressor genes, gene alteration
4. Experimental animal model of hepatocarcinogenesis

5. Conclusion

\section{General aspects of hepatocellular carcinoma}

Hepatocellular carcinoma (HCC) is the sixth most common cancer and third most frequent cause of cancer-related death worldwide (1-3). It has received considerable attention in recent years because of its rapid increase in incidence. Most HCC cases occur in sub-Saharan Africa and Eastern Asia. However, the incidence has been increasing in some developed countries including Japan, UK, France, and USA (1).

Chronic viral infection with the hepatitis $\mathrm{B}$ virus (HBV) or hepatitis $\mathrm{C}$ virus (HCV) appears to be the most significant causes of HCC (4). Chronic inflammation and regeneration of hepatocytes are underlying causes of HCC. Continuous inflammation occasionally damages DNA in the hepatocytes of the regenerating liver, thereby increasing the chances of gene alteration related to carcinogenesis.

Patients diagnosed with HCC have a poor prognosis because of the aggressive nature of the disease $(1,5)$. Surgical resection or local ablation therapy is effective only at an early stage of HCC. However, approximately $70 \%$ of these patients develop recurrent tumors within 5 years (6). Moreover, no effective chemotherapy exists for the advanced disease. Molecular target therapy, especially that targeting the angiogenesis pathway, is now developing as a novel anti-cancer modality $(7,8)$. This therapy seems to be a promising way of prolonging the survival of patients with advanced HCC.

Elucidation of the mechanism of hepatocarcinogenesis should contribute to the development of molecular target therapy. Although there is a growing understanding of the molecular mechanisms that induce hepatocarcinogenesis, real mechanisms of hepatocarcinogenesis have not been completely elucidated. However, cumulative knowledge regarding the molecular mechanisms of carcinogenesis revealed that the development and progression of HCC are caused by the accumulation of genetic changes, thus resulting in altered expression of cancer-related genes.

\section{Molecular alterations in human HCC}

p53. The p53 gene is the most extensively studied gene in the solid tumors. Mutation of this gene has been identified in a variety of human cancers (9-12). The $\mathrm{p} 53$ pathways have many 
crucial roles in cell cycle control, transcriptional regulation, and apoptosis $(13,14)$. Alteration of the p53 gene occurs at a relatively low frequency in $\mathrm{HCC}$ compared to other solid tumors. Epidemiologically p53 mutation was frequently found in aflatoxin-induced HCC $(\sim 50 \%)$, but was rare in HCC that was not induced by aflatoxin (28-42\%) (15-18). In a study of hepatitis $\mathrm{B}$ and $\mathrm{C}$, the p53 mutation profile was different for both; the p53 abnormality in HBV-related HCC (45\%) was significantly higher than that in HCV-related HCC (13\%) (19). HBX protein, encoded by HBV genome, has been reported to be a transcriptional transactivator protein. In a transgenic model, HBX protein induced progressive neoplastic changes in the liver (20). This protein binds to the p53 protein in the cytoplasm, resulting in the blockage of p53 entry into the nucleus.

$R b / p 16$. The retinoblastoma $(\mathrm{Rb})$ gene is another widely studied tumor suppressor gene in HCC and other solid tumors. It is a negative regulator of the cell cycle through its ability to bind the transcription factor E2F and to suppress the transcription of S-phase-related genes $(21,22)$. Mutations of $\mathrm{Rb}$ were found in only $15 \%$ of HCC cases (15). However, the loss of heterozygosity ( $\mathrm{LOH}$ ) of $13 \mathrm{q}$, where the $\mathrm{Rb}$ gene is located, occurred more frequently in $\mathrm{HCC}(25-48 \%)(23,24)$.

The p16 gene, also known as cyclin-dependent kinase inhibitor $2 \mathrm{~A}$ gene, is the regulator of the $\mathrm{Rb}$ pathway. Inactivation of either Rb or p16 was frequently found in HCC (81\%) (25). Alterations of the p16 gene occurred either by promoter hypermethylation or $\mathrm{LOH}$ of 9p in $\mathrm{HCC}(26,27)$.

PTEN. Phosphatase and tensin homolog (PTEN) is a tumor suppressor gene located on chromosome 10q. It negatively regulates the phosphoinositide 3-kinase/Akt signaling pathway, which is involved in the regulation of cell survival (28). Absence or reduced expression of PTEN was found in $\sim 40 \%$ of HCC cases (29).

RUNX3. Runt-related transcription factor 3 (RUNX3), located in chromosome 1p36, was first reported as a tumor suppressor gene for gastric cancer (30). RUNX3 is a potential tumor suppressor gene for $\mathrm{HCC}$, as the decreased mRNA expression of RUNX3 was observed in 50-92\% of HCC cases $(31,32)$. The significance of decreased expression of RUNX3 is related to dysfunction of cell cycle regulation, decrement of apoptosis $(33,34)$, enhancement of angiogenesis, and the development of epithelial-mesenchymal transition (35).

Most of gene alterations in tumor suppressor genes are due to $\mathrm{LOH}$ or promoter hypermethylation (36-39). Highest percentages of $\mathrm{LOH}$ were detected at several losi on chromosomes 8p, 4q, 4q, 17p, 16q, 6q, 1p and 9p in HCC (18). LOH of $17 \mathrm{p}$ and $9 \mathrm{p}$ are correlated with p53 and p16, respectively.

Oncogenes. The role of the oncogenes in HCC seems to be less important as compared to that of the tumor suppressor genes, in contrast to other types of cancer. Myc, located on chromosome 8q, is a potent proto-oncogene in HCC and other cancers. It codes for a protein involved in nucleic acid metabolism and in mediating the cellular response to growth factors. The correlation of myc expression and tumor size was reported (40). Inactivation of myc suppressed the progression of HCC in a mouse model (41).
Mutation of the 3 major ras proto-oncogenes ( $\mathrm{H}-, \mathrm{K}-$, and $\mathrm{N}$-ras) was found in only in few cases of HCCs (42-44). K-ras mutation was frequently found in vinyl chloride related HCC (45). Activating point mutations of the BRAF gene occurred in $14 \%$ of HCC cases (46).

Reactivation of developmental pathways. The Wnt//-catenin pathway plays an essential role in liver development. Activation of the catenin pathway frequently occurred in HCC (47). The gene related to adenomatous polyposis coli (APC), a crucial regulator of intestinal carcinogenesis, is also involved in hepatocarcinogenesis. APC expression was reduced in HCC (48). This reduction induces the activation of the $\beta$-catenin signaling pathway. Mutation of $\beta$-catenin was also observed in HCC (49); mutation of this pathway contributes to the activation of the Wnt signaling pathway.

Hedgehog signaling is another developmental pathway that is involved in hepatocarcinogenesis (50). Hedgehog plays an important role in early embryonic development (51). Sonic hedgehog, Indian hedgehog, and desert hedgehog are 3 mammalian hedgehog genes that have been identified. Two major groups of hedgehog-related proteins that have been identified are patched (PTCH) and smoothened (SMO) (52-54). These two molecules interact with each other. In the absence of ligand, PTCH inhibits SMO. When hedgehog reaches the PTCH receptor, it binds to PTCH and releases the repression of SMO. Gli proteins, which are downstream signaling molecules of SMO, act as transcription factors, thus resulting in the promotion of cell growth and inhibition of apoptosis (55). The transcription of hedgehog and related molecules was reported to be increased in some cases of HCC (56).

Growth factors and their receptors. The expression of several growth factors has been reported in HCC. Expression of the transforming growth factor- $\alpha$ (TGF- $\alpha$ ) was increased in most cases of HCCs (81\%) (57). TGF- $\alpha$ stimulates the proliferation of HCC cells by activating the epidermal growth factor receptor signaling pathway. Overexpression of TGF- $\alpha$ might be associated with hepatitis B infection (58).

The insulin-like growth factor-2 (IGF-2) signaling pathway is also involved in hepatocarcinogenesis. $\mathrm{LOH}$ or mutation of the IGF-2 receptor was frequently found $(25-55 \%)$ in $\operatorname{HCC}(59,60)$. Alteration of this receptor is related to the overexpression of mitogen IGF-2, because the receptor induces the degradation of IGF-2. The IGF-2 receptor also activates transforming growth factor- $\beta$ (TGF- $\beta$ ), a negative regulator of cell growth, by binding to the latent complex of TGF- $\beta$ (61). Alteration of the TGF- $\beta$ receptor type II gene itself was also found in HCC ( 10\%) (62).

Telomerase activity and telomere length. Telomere is a region of repetitive DNA at the end of each chromosome, which contributes to the stability and integrity of the chromosome (63). The length of the telomere is maintained by the activity of telomerase, which is a ribonucleoprotein complex composed of telomerase reverse transcriptase (TERT) and an RNA primer sequence. Without TERT, the length of the telomere gradually decreases (64). If the cells divide without telomeres, they would lose the end of their chromosomes that contain necessary information. Thus, the length of the telomere limits the lifespan of normal somatic cells (65). TERT activity has been found in 


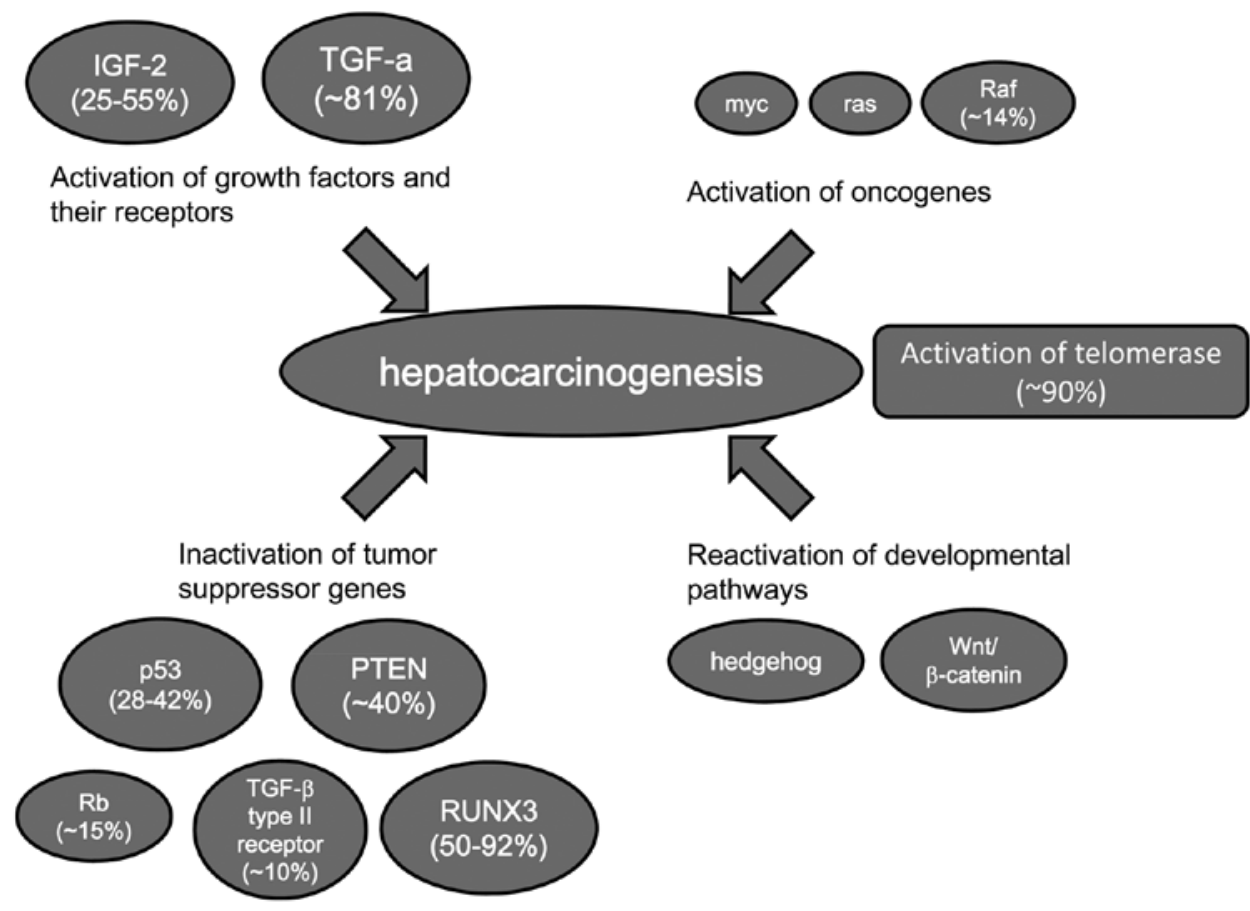

Figure 1. Gene alterations occurring in HCC. Gene alterations in human HCC are summarized; four major groups of genes are altered in HCC. Gene alterations of growth factors and tumor suppressor genes frequently occur in HCC.

most human cancers (66-69). Activation of telomerase was frequently $(\sim 90 \%)$ found in HCC $(70,71)$. The maintenance of telomere stability seems to be required for the immortalization of cancer cells. However, the mechanism by which telomerase is activated is not fully understood.

Many cancer-related genes are altered in HCC. However, since the frequency of alteration for each individual gene is relatively low, the accumulation of alterations of cancer-related genes may be necessary for hepatocarcinogenesis. Hepatocarcinogenesis is tightly associated with chronic hepatitis or liver cirrhosis in which there are persistent inflammation and cell division of hepatocytes. Continuous inflammation induces oxidative DNA damage, and then DNA repair occurs occasionally accompanied with DNA misrepair, resulting in increased mutation frequency. Constant activation of cell division and the increased chances of DNA replication errors are important factors for the development of HCC (Fig. 1).

\section{Experimental hepatocarcinogenesis in vitro}

Spontaneous immortalization. Normal human cultured cells are quite resistant to neoplastic transformation $(72,73)$, whereas rodent cultured cells are transformed to neoplastic cells with relative ease. This species difference is probably due to the difficulty in immortalizing normal human cells in vitro, because human cells are strictly predestined to cellular aging. As far as we know, neither spontaneous immortalization nor spontaneous neoplastic transformation of normal human hepatocytes has been reported.

DNA virus oncogenes. Oncogenic genes have been introduced in order to establish immortalized human hepatocytes. Various types of human cells can be immortalized with oncogenic genes from DNA viruses, such as simian virus 40 (SV40), adenovirus, and papillomavirus (74). Hepatocytes were successfully immortalized only by introducing the SV40 large T antigen (75); however, SV40 immortalization may have no relationship with hepatocarcinogenesis. Furthermore, there is no evidence that SV40 is related to human cancer (76).

Retrovirus oncogenes. In studies of other types of cells, myc and ras were able to immortalize human fibroblasts and epithelial cells, respectively $(77,78)$. These retroviral oncogenes are related to at least a few cases of HCC. However, there has been no report that these genes successfully immortalize human hepatocytes.

HCV core protein. $\mathrm{HCV}$ core protein is known to induce oxidative stress, steatosis, and HCC in the patient with HCV (79). Ray et al introduced HCV core genomic region into primary human hepatocyte (80). Those cells became immortalized and exhibited continuous cell growth. Immortalization is necessary but not sufficient for hepatocarcinogenesis. However, $\mathrm{HCV}$ core protein transgenic mice developed HCC after the age of 16 months (81). Thus HCV core protein may relate to an important process in the multistep hepatocarcinogenesis.

Chemical treatment and ionizing radiation. Although exposure to some chemical agents is closely related to human HCC, no successful malignant transformation of human hepatocytes by chemical agents or ionizing radiation in vitro has been reported.

Characterization of immortalized human hepatocytes. Several human hepatocyte cell lines were established by transfection of SV40 T-antigen. THLE-2 and THLE-3 cells were established 


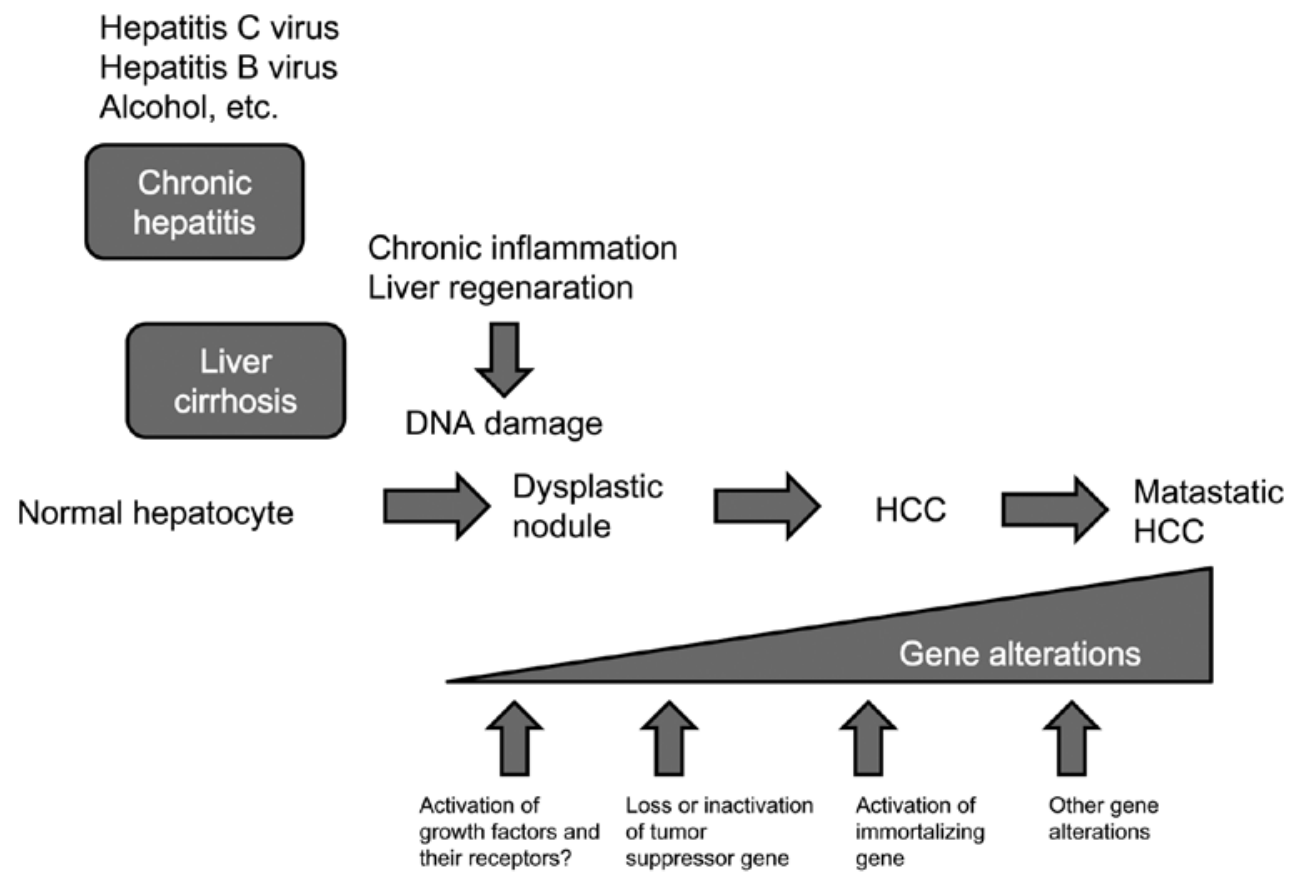

Figure 2. Sequential gene alterations in the human liver leading to HCC. Chronologic sequence of the development of human HCC and gene alterations; HCC develops in the setting of chronic inflammation due to viral hepatitis or alcoholic liver injury. Hepatocarcinogenesis may begin in dysplastic nodules consisting of pre-neoplastic hepatocytes. Accumulation of gene alterations in dysplastic hepatocytes leads to HCC. Further gene alterations are responsible for the malignant transformation of HCC.

from an adult human liver autopsy sample (82). These cells were non-tumorigenic, but the population doubling levels of these cell lines were more than 100 . These cell lines were established from liver epithelial cells, and they expressed albumin and cytokeratin 18 in early passages, thus suggesting that they expressed features of both hepatocytes and non-parenchymal cells. In a study of hepatocyte-specific functions of these cell lines, activities of the enzymes including cytochrome P-450 reductase, nicotinamide adenine dinucleotide phosphate, superoxide dismutase, catalase, glutathione S-transferase, and epoxide hydrolase were maintained.

Immortalized human hepatocytes were also established from surgically resected human adult liver by Schippers $\mathrm{et} \mathrm{al}$, using the SV40 T-antigen (75). These hepatocytes retained albumin secretion equivalent to that of normal primary human hepatocyte. Though there was no description of liver-specific enzymes, such as cytochrome P-450 reductase activity, their immortalized hepatocytes retained polarity, which is important for the formation of bile canaliculi. Interestingly, these hepatocytes maintained the multidrug-resistant P-glycoprotein, which is essential for the removal of toxic metabolites.

We established another immortalized human hepatocyte OUMS-29 from human embryonic liver using SV40 T-antigen (83). OUMS-29 cells have a population doubling level of more than 900 . These cells produce liver-specific proteins, including albumin, transferrin, $\alpha$-antitrypsin, and apolipoprotein A1. Furthermore, these cells also retain cytochrome $\mathrm{P}-450$ reductase activity.

The study of in vitro carcinogenesis of human hepatocytes has shown that only the introduction of SV40 large T antigen can successfully immortalize cells. A major difficulty in the in vitro induction of carcinogenesis of human hepatocytes is the inadequacy of the available methods of culturing human hepatocytes. To solve this problem, methods of culturing human liver cells with hepatocyte characteristics need to be developed in the future.

The introduction of TERT might be a useful method for human hepatocyte carcinogenesis. TERT introduction into human primary hepatocytes increases the population doubling level, thus providing easy in vitro culture of primary hepatocytes.

Since telomerase activation is a common feature in HCC, telomerase activity may play a key role in hepatocarcinogenesis, especially in immortalization, because the immortalization of the cell is the initial step in the neoplastic transformation process. However, the cause and effect relationship between telomerase activation and hepatocarcinogenesis has not been elucidated yet.

\section{Experimental animal model of hepatocarcinogenesis}

Animal models of carcinogenesis play a critical role in understanding the mechanism of carcinogenesis. Many experimental hepatocarcinogenesis models have been developed (reviewed in ref. 84).

The H-ras or B-raf mutation was frequently found in rodent liver tumors $(85,86)$; however, these mutations were infrequent in human HCC. The difference in gene alteration between rodent $\mathrm{HCC}$ and human $\mathrm{HCC}$ was also found in p53 mutations. Mouse HCCs generally lack p53 mutations, whereas this mutation is relatively frequent in human HCCs (18-50\%) (87). This species difference needs to be considered in order to elucidate the molecular mechanism of human hepatocarcinogenesis. In spite of the species difference, animal models are still useful 
tools in understanding the process of development especially for the early stages of hepatocarcinogenesis.

\section{Conclusion}

As in the case of other types of human cancers, hepatocarcinogenesis seems to be a multistep process in which multiple cancer-related genes are altered. These genetic changes are related to tumor suppressor genes, oncogenes, reactivation of developmental pathways, and growth factors and their receptors. Although numerous genes are altered in HCC, the frequency of each individual gene alteration is relatively low. Telomerase activation is the common feature of HCC and is closely related to immortalization. Thus, telomerase activation may be the common effect of cancer-related genes (Fig. 2).

Neoplastic transformation of human hepatocytes has not yet been achieved in an in vitro model of human hepatocarcinogenesis. Normal human cells are quite resistant to neoplastic transformation. Although several human immortalized hepatocyte cell lines have been established, they have been immortalized only by introducing with the SV40 large $\mathrm{T}$ antigen. Given that immortalization is only an initial step of the neoplastic transformation process, immortalized human hepatocytes can become useful tools for the elucidation of hepatocarcinogenesis, especially for the initial step of multistep hepatocarcinogenesis.

\section{References}

1. El-Serag HB and Rudolph KL: Hepatocellular carcinoma: epidemiology and molecular carcinogenesis. Gastroenterology 132 $2557-2576,2007$

2. Garcia M, Jernal A, Ward EM, et al: Global Cancer Facts \& Figures 2007. Journal 2007.

3. Parkin DM, Pisani P and Ferlay J: Global cancer statistics. CA Cancer J Clin 49: 33-64, 1999

4. Bosch FX, Ribes J and Borras J: Epidemiology of primary liver cancer. Semin Liver Dis 19: 271-285, 1999.

5. El-Serag HB and Mason AC: Rising incidence of hepatocellular carcinoma in the United States. N Engl J Med 340: 745-750, 1999.

6. Nakakura EK and Choti MA: Management of hepatocellular carcinoma. Oncology (Williston Park) 14: 1085-1102, 2000.

7. El-Serag HB, Marrero JA, Rudolph L and Reddy KR: Diagnosis and treatment of hepatocellular carcinoma. Gastroenterology 134: 1752-1763, 2008.

8. Llovet JM, Ricci S, Mazzaferro V, et al: Sorafenib in advanced hepatocellular carcinoma. N Engl J Med 359: 378-390, 2008.

9. Nigro JM, Baker SJ, Preisinger AC, et al: Mutations in the p53 gene occur in diverse human tumour types. Nature 342: 705-708, 1989.

10. Levine AJ, Momand J and Finlay CA: The p53 tumour suppressor gene. Nature 351: 453-456, 1991.

11. Hollstein M, Sidransky D, Vogelstein B and Harris CC: p53 mutations in human cancers. Science 253: 49-53, 1991.

12. Bressac B, Galvin KM, Liang TJ, Isselbacher KJ, Wands JR and Ozturk M: Abnormal structure and expression of p53 gene in human hepatocellular carcinoma. Proc Natl Acad Sci USA 87: 1973-1977, 1990

13. Bourdon JC: p53 and its isoforms in cancer. Br J Cancer 97: 277-282, 2007

14. Vousden KH and Lane DP: p53 in health and disease. Nat Rev Mol Cell Biol 8: 275-283, 2007.

15. Ozturk M: Genetic aspects of hepatocellular carcinogenesis. Semin Liver Dis 19: 235-242, 1999.

16. Tannapfel A, Busse C, Weinans L, et al: INK4a-ARF alterations and p53 mutations in hepatocellular carcinomas. Oncogene 20 7104-7109, 2001

17. Bressac B, Kew M, Wands J and Ozturk M: Selective G to T mutations of p53 gene in hepatocellular carcinoma from southern Africa. Nature 350: 429-431, 1991.
18. Buendia MA: Genetics of hepatocellular carcinoma. Semin Cancer Biol 10: 185-200, 2000.

19. Teramoto T, Satonaka K, Kitazawa S, Fujimori T, Hayashi K and Maeda S: p53 gene abnormalities are closely related to hepatoviral infections and occur at a late stage of hepatocarcinogenesis. Cancer Res 54: 231-235, 1994.

20. Ueda H, Ullrich SJ, Gangemi JD, et al: Functional inactivation but not structural mutation of p53 causes liver cancer. Nat Genet 9: 41-47, 1995

21. Pantoja E, Beecher TS and Cross VF: Cutaneous lymphangiosarcoma of Stewart-Treves. Cutis 17: 883-886, 1976.

22. Hanahan D and Weinberg RA: The hallmarks of cancer. Cell 100: $57-70,2000$

23. Higashitsuji $\mathrm{H}$, Itoh $\mathrm{K}$, Nagao $\mathrm{T}$, et al: Reduced stability of retinoblastoma protein by gankyrin, an oncogenic ankyrin-repeat protein overexpressed in hepatomas. Nat Med 6: 96-99, 2000.

24. Hsia CC, Di Bisceglie AM, Kleiner DE Jr, Farshid M and Tabor E: RB tumor suppressor gene expression in hepatocellular carcinomas from patients infected with the hepatitis B virus. J Med Virol 44: 67-73, 1994.

25. Azechi H, Nishida N, Fukuda Y, et al: Disruption of the p16/ cyclin D1/retinoblastoma protein pathway in the majority of human hepatocellular carcinomas. Oncology 60: 346-354, 2001.

26. Liew CT, Li HM, Lo KW, et al: High frequency of p16INK4A gene alterations in hepatocellular carcinoma. Oncogene 18: 789-795, 1999.

27. Matsuda Y, Ichida T, Matsuzawa J, Sugimura K and Asakura H: p16(INK4) is inactivated by extensive CpG methylation in human hepatocellular carcinoma. Gastroenterology 116: 394-400, 1999.

28. Li DM and Sun H: PTEN/MMAC1/TEP1 suppresses the tumorigenicity and induces G1 cell cycle arrest in human glioblastoma cells. Proc Natl Acad Sci USA 95: 15406-15411, 1998.

29. Hu TH, Huang CC, Lin PR, et al: Expression and prognostic role of tumor suppressor gene PTEN/MMAC1/TEP1 in hepatocellular carcinoma. Cancer 97: 1929-1940, 2003.

30. Li QL, Ito K, Sakakura C, et al: Causal relationship between the loss of RUNX3 expression and gastric cancer. Cell 109: 113-124, 2002.

31. Mori T, Nomoto S, Koshikawa K, et al: Decreased expression and frequent allelic inactivation of the RUNX3 gene at $1 \mathrm{p} 36$ in human hepatocellular carcinoma. Liver Int 25: 380-388, 2005.

32. Miyagawa K, Sakakura C, Nakashima S, et al: Down-regulation of RUNX1, RUNX3 and CBFbeta in hepatocellular carcinomas in an early stage of hepatocarcinogenesis. Anticancer Res 26 : 3633-3643, 2006.

33. Li X, Zhang Y, Qiao T, et al: RUNX3 inhibits growth of HCC cells and HCC xenografts in mice in combination with adriamycin. Cancer Biol Ther 7: 669-676, 2008.

34. Nakanishi Y, Shiraha H, Nishina S, et al: Loss of runt-related transcription factor 3 expression leads hepatocellular carcinoma cells to escape apoptosis. BMC Cancer 11: 3, 2011.

35. Tanaka S, Shiraha H, Nakanishi Y, et al: Runt-related transcription factor 3 reverses epithelial-mesenchymal transition in hepatocellular carcinoma. Int J Cancer 131: 2537-2546, 2012.

36. Fujimoto Y, Hampton LL, Wirth PJ, Wang NJ, Xie JP and Thorgeirsson SS: Alterations of tumor suppressor genes and allelic losses in human hepatocellular carcinomas in China. Cancer Res 54: 281-285, 1994.

37. Kawai H, Suda T, Aoyagi Y, et al: Quantitative evaluation of genomic instability as a possible predictor for development of hepatocellular carcinoma: comparison of loss of heterozygosity and replication error. Hepatology 31: 1246-1250, 2000.

38. Nishida N, Nagasaka T, Nishimura T, Ikai I, Boland CR and Goel A: Aberrant methylation of multiple tumor suppressor genes in aging liver, chronic hepatitis, and hepatocellular carcinoma. Hepatology 47: 908-918, 2008.

39. Yang B, Guo M, Herman JG and Clark DP: Aberrant promoter methylation profiles of tumor suppressor genes in hepatocellular carcinoma. Am J Pathol 163: 1101-1107, 2003.

40. Wang Y, Wu MC, Sham JS, Zhang W, Wu WQ and Guan XY: Prognostic significance of c-myc and AIB1 amplification in hepatocellular carcinoma. A broad survey using high-throughput tissue microarray. Cancer 95: 2346-2352, 2002

41. Shachaf CM, Kopelman AM, Arvanitis C, et al: MYC inactivation uncovers pluripotent differentiation and tumour dormancy in hepatocellular cancer. Nature 431: 1112-1117, 2004.

42. Tada M, Omata M and Ohto M: Analysis of ras gene mutations in human hepatic malignant tumors by polymerase chain reaction and direct sequencing. Cancer Res 50: 1121-1124, 1990. 
43. Challen C, Guo K, Collier JD, Cavanagh D and Bassendine MF: Infrequent point mutations in codons 12 and 61 of ras oncogenes in human hepatocellular carcinomas. J Hepatol 14: 342-346, 1992.

44. Stork P, Loda M, Bosari S, Wiley B, Poppenhusen K and Wolfe H: Detection of K-ras mutations in pancreatic and hepatic neoplasms by non-isotopic mismatched polymerase chain reaction. Oncogene 6: 857-862, 1991.

45. Weihrauch M, Benick M, Lehner G, et al: High prevalence of K-ras-2 mutations in hepatocellular carcinomas in workers exposed to vinyl chloride. Int Arch Occup Environ Health 74: 405-410, 2001.

46. Davies H, Bignell GR, Cox C, et al: Mutations of the BRAF gene in human cancer. Nature 417: 949-954, 2002.

47. de La Coste A, Romagnolo B, Billuart P, et al: Somatic mutations of the beta-catenin gene are frequent in mouse and human hepatocellular carcinomas. Proc Natl Acad Sci USA 95: 8847-8851, 1998.

48. Csepregi A, Rocken C, Hoffmann J, et al: APC promoter methylation and protein expression in hepatocellular carcinoma. J Cancer Res Clin Oncol 134: 579-589, 2008.

49. Legoix P, Bluteau O, Bayer J, et al: Beta-catenin mutations in hepatocellular carcinoma correlate with a low rate of loss of heterozygosity. Oncogene 18: 4044-4046, 1999.

50. Huang S, He J, Zhang X, et al: Activation of the hedgehog pathway in human hepatocellular carcinomas. Carcinogenesis 27: 1334-1340, 2006.

51. Nusslein-Volhard C and Wieschaus E: Mutations affecting segment number and polarity in Drosophila. Nature 287: 795-801, 1980.

52. Nybakken $\mathrm{K}$ and Perrimon N: Hedgehog signal transduction: recent findings. Curr Opin Genet Dev 12: 503-511, 2002.

53. Cohen MM Jr and Shiota K: Teratogenesis of holoprosencephaly. Am J Med Genet 109: 1-15, 2002.

54. Mullor JL, Sanchez P and Ruiz i Altaba A: Pathways and consequences: Hedgehog signaling in human disease. Trends Cell Biol 12: 562-569, 2002 .

55. Stecca B, Mas C and Ruiz i Altaba A: Interference with HH-GLI signaling inhibits prostate cancer. Trends Mol Med 11: 199-203, 2005.

56. Patil MA, Zhang J, Ho C, Cheung ST, Fan ST and Chen X: Hedgehog signaling in human hepatocellular carcinoma. Cancer Biol Ther 5: 111-117, 2006.

57. Schaff Z, Hsia CC, Sarosi I and Tabor E: Overexpression of transforming growth factor-alpha in hepatocellular carcinoma and focal nodular hyperplasia from European patients. Hum Pathol 25: 644-651, 1994.

58. Hsia CC, Axiotis CA, Di Bisceglie AM and Tabor E: Transforming growth factor-alpha in human hepatocellular carcinoma and coexpression with hepatitis B surface antigen in adjacent liver. Cancer 70: 1049-1056, 1992

59. Yamada T, De Souza AT, Finkelstein S and Jirtle RL: Loss of the gene encoding mannose 6-phosphate/insulin-like growth factor II receptor is an early event in liver carcinogenesis. Proc Natl Acad Sci USA 94: 10351-10355, 1997.

60. De Souza AT, Hankins GR, Washington MK, Orton TC and Jirtle RL: M6P/IGF2R gene is mutated in human hepatocellular carcinomas with loss of heterozygosity. Nat Genet 11: 447-449, 1995.

61. Dennis PA and Rifkin DB: Cellular activation of latent transforming growth factor beta requires binding to the cation-independent mannose 6-phosphate/insulin-like growth factor type II receptor. Proc Natl Acad Sci USA 88: 580-584, 1991.

62. Kawate S, Takenoshita S, Ohwada S, et al: Mutation analysis of transforming growth factor beta type II receptor, Smad2, and Smad4 in hepatocellular carcinoma. Int J Oncol 14: 127-131, 1999.

63. Harley CB: Telomere loss: mitotic clock or genetic time bomb? Mutat Res 256: 271-282, 1991.

64. Harley CB, Futcher AB and Greider CW: Telomeres shorten during ageing of human fibroblasts. Nature 345: 458-460, 1990.

65. Counter CM, Avilion AA, LeFeuvre CE, et al: Telomere shortening associated with chromosome instability is arrested in immortal cells which express telomerase activity. EMBO J 11: 1921-1929, 1992
66. Kim NW, Piatyszek MA, Prowse KR, et al: Specific association of human telomerase activity with immortal cells and cancer. Science 266: 2011-2015, 1994.

67. Counter CM, Hirte HW, Bacchetti S and Harley CB: Telomerase activity in human ovarian carcinoma. Proc Natl Acad Sci USA 91: 2900-2904, 1994.

68. Hiyama E, Gollahon L, Kataoka T, et al: Telomerase activity in human breast tumors. J Natl Cancer Inst 88: 116-122, 1996

69. Shay JW and Bacchetti S: A survey of telomerase activity in human cancer. Eur J Cancer 33: 787-791, 1997.

70. Kojima H, Yokosuka O, Imazeki F, Saisho H and Omata M: Telomerase activity and telomere length in hepatocellular carcinoma and chronic liver disease. Gastroenterology 112: 493-500, 1997.

71. Nagao K, Tomimatsu M, Endo H, Hisatomi H and Hikiji K Telomerase reverse transcriptase mRNA expression and telomerase activity in hepatocellular carcinoma. J Gastroenterol 34: 83-87, 1999.

72. Namba M, Mihara K and Fushimi K: Immortalization of human cells and its mechanisms. Crit Rev Oncog 7: 19-31, 1996.

73. McCormick JJ and Maher VM: Towards an understanding of the malignant transformation of diploid human fibroblasts. Mutat Res 199: 273-291, 1988.

74. Linder S and Marshall H: Immortalization of primary cells by DNA tumor viruses. Exp Cell Res 191: 1-7, 1990.

75. Schippers IJ, Moshage H, Roelofsen H, et al: Immortalized human hepatocytes as a tool for the study of hepatocytic (de-)differentiation. Cell Biol Toxicol 13: 375-386, 1997.

76. Strickler HD, Rosenberg PS, Devesa SS, Hertel J, Fraumeni JF Jr and Goedert JJ: Contamination of poliovirus vaccines with simian virus 40 (1955-1963) and subsequent cancer rates. JAMA 279: 292-295, 1998.

77. Faller DV, Kourembanas S, Ginsberg D, et al: Immortalization of human endothelial cells by murine sarcoma viruses, without morphologic transformation. J Cell Physiol 134: 47-56, 1988.

78. Morgan TL, Yang DJ, Fry DG, et al: Characteristics of an infinite life span diploid human fibroblast cell strain and a near-diploid strain arising from a clone of cells expressing a transfected v-myc oncogene. Exp Cell Res 197: 125-136, 1991.

79. Moriya K, Nakagawa K, Santa T, et al: Oxidative stress in the absence of inflammation in a mouse model for hepatitis $\mathrm{C}$ virusassociated hepatocarcinogenesis. Cancer Res 61: 4365-4370, 2001.

80. Ray RB, Meyer K and Ray R: Hepatitis C virus core protein promotes immortalization of primary human hepatocytes Virology 271: 197-204, 2000.

81. Moriya K, Fujie H, Shintani Y, et al: The core protein of hepatitis $\mathrm{C}$ virus induces hepatocellular carcinoma in transgenic mice. Nat Med 4: 1065-1067, 1998

82. Pfeifer AM, Cole KE, Smoot DT, et al: Simian virus 40 large tumor antigen-immortalized normal human liver epithelial cells express hepatocyte characteristics and metabolize chemical carcinogens. Proc Natl Acad Sci USA 90: 5123-5127, 1993.

83. Fukaya K, Asahi S, Nagamori S, et al: Establishment of a human hepatocyte line (OUMS-29) having CYP 1A1 and 1A2 activities from fetal liver tissue by transfection of SV40 LT. In Vitro Cell Dev Biol Anim 37: 266-269, 2001.

84. Schaff Z, Kovalszky I, Nagy P, Zalatnai A, Jeney A and Lapis K Human and experimental hepatocarcinogenesis. Scand J Gastroenterol (Suppl) 228: 90-97, 1998 .

85. Buchmann A, Ziegler S, Wolf A, Robertson LW, Durham SK and Schwarz M: Effects of polychlorinated biphenyls in rat liver: correlation between primary subcellular effects and promoting activity. Toxicol Appl Pharmacol 111: 454-468, 1991.

86. Jaworski M, Hailfinger S, Buchmann A, et al: Human p 53 knock-in (hupki) mice do not differ in liver tumor response from their counterparts with murine p53. Carcinogenesis 26: 1829-1834, 2005.

87. Unger C, Buchmann A, Bunemann CL, Kress S and Schwarz M: Wild-type function of the p53 tumor suppressor protein is not required for apoptosis of mouse hepatoma cells. Cell Death Differ 5: 87-95, 1998. 